\title{
The Possible Role of the Incretin Enhancer Sitaglipten, in Renal Ischemic Reperfusion Injury in Type 2 Diabetes Mellitus
}

\author{
Mervat E. Mohamed*, Sammy H. Hammadi, Magda H. Abd-El Hamid \\ Department of Pharmacology \& Toxicology and Pathology, Faculty of Medicine, Umm Al-Qura University, \\ Makkah, Saudi Arabia \\ Email: ${ }^{*}$ mervat vip@yahoo.com
}

Received 26 May 2014; revised 26 June 2014; accepted 8 July 2014

Copyright (C) 2014 by authors and Scientific Research Publishing Inc.

This work is licensed under the Creative Commons Attribution International License (CC BY). http://creativecommons.org/licenses/by/4.0/

(c) (i) Open Access

\section{Abstract}

Background: Diabetes mellitus (DM) especially type 2 is a major health problem and diabetic nephropathy is the main cause of end stage renal disease (ESRD). Renal ischemia/reperfusion (I/R) injury is common in diabetic patients. Recent studies reported increased vulnerability of kidneys to $I / R$ injury in diabetic rats. In view of the reported efficacy of incretin enhancer on $I / R$ injury. Aim: This study was designed to assess the effect of sitaglipten on renal $I / R$ in type 2 diabetes mellitus . Methods: Type $2 \mathrm{DM}$ in rats were induced by administration of nicotinamide $(230 \mathrm{mg} / \mathrm{kg}$, i.p.), $15 \mathrm{~min}$ prior to the single dose of streptozotocin $(65 \mathrm{mg} / \mathrm{kg}$, i.p.). Renal I/R were performed in both diabetic and normal rats. Results: The lipid peroxidation, xanthine oxidase activity, and nitric oxide levels were significantly increased after $I / R$ in diabetic rats compared to $I / R$ in normal rats. Antioxidant enzymes such as glutathione, superoxide dismutase, catalase, and glutathione peroxidase were significantly reduced after $I / R$ in diabetic rats compared to normal rats. Sitaglipten treatment significantly normalized these biochemical parameters compared to diabetic I/R rats. Serum TNF- $\alpha$ level and myeloperoxidase activity were also significantly normalized after administration of sitaglipten. Furthermore, treatment with sitaglipten $(10 \mathrm{mcg} / \mathrm{kg}) \mathrm{had}$ preserved the normal morphology of the kidney compared to I/R performed in diabetic rats. Conclusion: Sitaglipten protects exaggerated renal I/R injury in type $2 \mathrm{DM}$. These findings have major implication in the treatment of ischemic injury that is prone to develop in DM.

\section{Keywords}

Type 2 Diabetes Mellitus, Dipeptidyl Peptidase-IV, Glucagon-Like Peptide-1, Sitaglipten, Inflammation, Ischemia Reperfusion, Kidney, Oxidative Stress

\footnotetext{
"Corresponding author.
} 


\section{Introduction}

Type 2 diabetes mellitus or non-insulin-dependent diabetes mellitus (NIDDM) is one of the leading causes of end-stage renal disease (ESRD) [1]. Diabetic patients are at a higher risk of ischemic changes compared to nondiabetics [2]. With increasing duration and severity of ischemia, greater cell damage can develop [3] [4]. The mechanisms behind the injury in diabetic nephropathy are not fully understood despite intense researches. Diabetic patients may need renal transplantation in their later life due to diabetic nephropathy. The short period of ischemia (30 $\mathrm{min}$ ) in diabetes has been demonstrated to lead to reversible renal failure, however progressive injury lead to ESRD [4]. Reactive oxygen species (ROS) and nitric oxide (NO) play an important role in mediating cell damage during ischemia-reperfusion (I/R) injury [5]. Inflammation contributes substantially to the pathogenesis of $\mathrm{I} / \mathrm{R}$ with a central role for particular cells, adhesion molecules, and cytokines [6]. Neutrophils produce abundantly ROS during I/R injury. Myeloperoxidase (MPO) is found in neutrophils, which catalyze the formation of hypochlorous acid ( $\mathrm{HOCl}$ ), a toxic agent to cellular components, and initiates oxidative injury [7]. Renal I/R injury may cause oxidative stress and increase lipid peroxidation in the tissue.

Although many antidiabetic drugs have been developed and used for treatment so far, current treatment strategies for type 2 diabetes have only limited long-term efficacy and tolerability given the progressive nature of the disease [8]. As such, there is a need to develop efficient new therapeutic strategies for the treatment of type 2 DM. Primary defects of insulin action (insulin resistance), along with a defect of insulin secretion, contribute to the etiology of this type of diabetes. Diminished postprandial insulin secretion resulting from both functional defects and the loss of surviving pancreatic $\beta$-cells is known to progress into hyperglycemia and a decline in insulin sensitivity [9]. Of the currently available oral antidiabetic agents, sulfonylureas have a superior postprandial antihyperglycemic effect due to their potent insulinotropic action. These agents are widely used by many diabetic patients, and there are few primary nonresponders [10] [11]. However, sulfonylureas potently and persistently stimulate insulin secretion irrespective of blood glucose levels, thereby causing hypoglycemia, which is a common undesirable side effect [12].

During the investigation of new antidiabetic drugs that do not have the disadvantages of sulfonylureas, glucagon-like peptide 1 (GLP-1), an incretin analogue, attracted attention. GLP-1, which is a 30 amino acid hormone secreted from L cells of the small intestine and proximal colon in response to the ingestion of nutrients, promotes insulin secretion through GLP-1 receptors expressed on pancreatic $\beta$-cells [13]. In addition, the insulinotropic action of GLP-1 is glucose-dependent; therefore, the risk of hypoglycemia is minimized [14]. However, the therapeutic use of GLP-1 is severely compromised by its lack of oral activity as well as its rapid degradation and inactivation by dipeptidyl peptidase (DPP)-IV, a serine protease that is present in soluble form in body fluids and is also expressed in many tissues, including the kidney and liver [15]. Thus, DPP-IV inhibitors, which prevent the proteolytic degradation of GLP-1 and enhance glucose-dependent insulin secretion from pancreatic $\beta$-cells, are a useful new class of antidiabetic drugs with a lower risk of inducing hypoglycemia than conventional sulfonylureas. Furthermore, clinical efficacy has been reported for DPP-IV inhibitors such as sitagliptin, vildagliptin, and saxagliptin [16]-[18]. GLP-1 receptor agonist (exenatide) has reported efficacy in ischemia reperfusion (I/R) injury [19] [20].

Aim: So far, little is known regarding the effect of sitaglipten on renal I/R in type $2 \mathrm{DM}$, and therefore, this study was designed to investigate its effect on renal I/R in diabetic rats.

\section{Materials and Methods}

\subsection{Chemicals}

Superoxide dismutase (SOD), crystalline beef liver catalase (CAT), 1, 1, 3, 3-tetrahydroxy-propane, glutathione (GSH), and epinephrine hydrochloride. Ethidium bromide, agarose, tris buffer, thiobarbituric acid, trichloroacetic acid, and Folin's phenol reagent. The diagnostic kits were used for estimation of BUN and creatinine. All other chemicals used in the study were of laboratory grade.

\subsection{Experimental Groups and Animals}

\section{Experimental Animals}

Fifty adult male albino rats weighing $250 \pm 10$ g were used in this study. All rats had free access to standard chow diet and tap water. They were housed in metabolic cages at $20^{\circ} \mathrm{C}-25^{\circ} \mathrm{C}$ and kept under constant condi- 
tions with 12/12 h light/dark cycles and left for acclimatization for one week before the start of the study. The care and handling of the animals were in accordance with the guidelines of the National Institutes of Health (NIH).

The rats were divided into five different groups, each of 10 rats $(n=10)$.

Group-1: Normal sham-operated (underwent all surgical procedures without I/R in normal rats).

Group-2: Diabetic sham-operated (underwent all surgical procedures without I/R in diabetic rats).

Group-3: (I/R control), in normal rats; on day 28, ischemia was produced for $30 \mathrm{~min}$, followed by reperfusion for 24 hours (hrs)

Group-4: (DM + I/R control), after induction of diabetes; on day 28, I/R was produced.

Group-5: (Sitaglipten treated group + I/R), in diabetic rats; on day 14, rats were given sitaglipten (10 mg per $\mathrm{kg}$ of body weight per day, P.O) [21] (Sigma, St.Louis, MO) then, on day 28, I/R was produced (Figure 1).

\subsection{Methods}

\subsubsection{Induction of DM and Measurement of Blood Glucose Level}

Diabetes mellitus in rats were induced by administration of nicotinamide (NIC) (230 mg/kg, i.p.), 15 min prior to a single intraperitoneal (i.p.) injection of streptozotocin $(65 \mathrm{mg} / \mathrm{kg}$, STZ) dissolved in di-sodium citrate buffer (pH 4.5) in a dose volume of $1 \mathrm{ml} / \mathrm{kg}$ body weight [22]. Control animals were received an equal volume of saline. After one week following NIC and STZ administration, blood was collected from tail vein after overnight fasting rats for $16 \mathrm{hrs}$, and serum samples were analyzed for blood glucose(by using standard diagnostic kits). Animals showing fasting blood glucose higher than $250 \mathrm{mg} / \mathrm{dl}$ were considered as diabetic and used for the further study. Four weeks elapsed in between the induction of diabetes and ischemic injury.

STZ \&NIC and sitaglipten were purchased from (Sigma Chemical Company Cairo, Egypt). Sitaglipten was given orally once a day by gastric tube at a dose of $10 \mathrm{mg} / \mathrm{kg}$ and was dissolved in distilled water and given orally for diabetic rats for two weeks. A similar volume of water was given to the other four groups orally once a day by gastric tube for two weeks (Placebo).

\subsubsection{Renal I/R Injury}

Diabetic and normal rats were anesthetized with ketamine (60 mg/kg i.p.) and diazepam (5 mg/kg i.p.). After anesthesia, the animal was fixed in supine position on the operating table and the abdominal skin was shaved and disinfected with povidone-iodine solution. All rats were undergoing surgical exposure of the left and right renal pedicles via midline incision. To induce renal ischemia, both renal pedicles were occluded for 30 min using a non-traumatic vascular clamp (Bulldog clamp). After removal of the vascular clamp, the abdomen was properly irrigated with isotonic saline, and then the abdominal incision was closed by continuous stitches using vicryl 2/0 sutures.

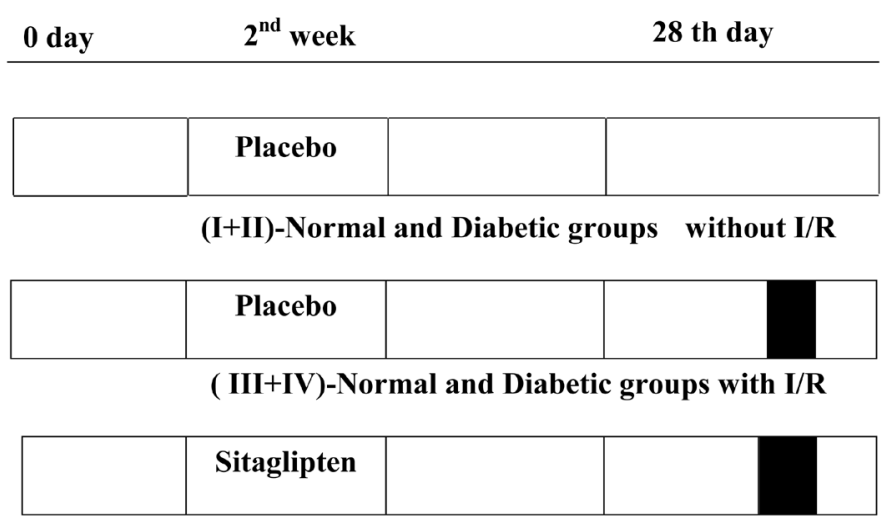

(V)-Sitaglipten treated group (sitaglipten+Diabetic+I/R)

Figure 1. Scheme representing the experimental protocols employed. Each protocol comprised the following periods: treatment period (Placebo or sitagliptin) 14 days before induction of ischemia. Ischemia for $30 \mathrm{~min}$ and reperfusion for $24 \mathrm{hrs}$. 


\subsubsection{Collection of Blood Samples}

Blood samples were taken (24 hrs after ischemia) using capillary tubes introduced into the medial retro-orbital venous plexus. Sera were separated from clotted blood after 20 - $30 \mathrm{~min}$ by centrifugation at $4000 \mathrm{rpm}$ for 15 min then divided into aliquots and kept at $-20^{\circ} \mathrm{C}$ for assay of blood urea nitrogen (BUN) (Jaffe's method), and creatinine (DAM method) by using standard diagnostic kits, while serum glucose was determined immediately.

\subsubsection{Determination of Serum Glucose, BUN, Creatinine, and TNF- $\alpha$}

Serum glucose was determined by using diagnostic kits (Spinreact, Spain), following the manufacturer instructions. BUN was estimated by using commercial kits (Spinreact, Spain), following the manufacturer instructions. Serum creatinine was determined by using auto analyzer apparatus (CX7, Beckman, USA). Serum TNF- $\alpha$ was determined by using an enzyme-linked immunosorbent assay (ELISA) according to the manufacturer's instructions.

\subsubsection{Harvesting of Kidney Specimen}

Kidney specimens were harvested 24 hrs after ischemia. Animals were anaesthetized with high dose of sodium thiopental i.p. Then, abdomen was rapidly opened and kidneys were removed rapidly, one was placed in $10 \%$ neutral buffered formalin for $\mathrm{H}$ and $\mathrm{E}$ staining and the other one was rapidly frozen in liquid nitrogen, and stored at $-70^{\circ} \mathrm{C}$ until tested.

\subsubsection{Lipid Peroxidation and Antioxidant Enzymes}

The kidney was cross-chopped with surgical scalpel into fine slices in chilled $0.25 \mathrm{M}$ sucrose, quickly blotted on a filter paper. The tissue was minced and homogenized in $10 \mathrm{mM}$ Tris-HCl buffer, $\mathrm{pH} 7.4(10 \% \mathrm{w} / \mathrm{v})$ with 25 strokes of tight Teflon pestle of a glass homogenizer at a speed of $2500 \mathrm{rpm}$. The clear supernatant was used for assays of lipid peroxidation (MDA content) and endogenous antioxidant enzymes such as superoxide dismutase (SOD), catalase (CAT), reduced glutathione (GSH), and glutathione peroxidase (GSHPx). The MDA formation was estimated by the method of Slater and Sawyer [23]. Reduced GSH was determined by the method of Moran et al. [24]. SOD was determined by the method of Mishra and Fridovich [25]. Catalase was estimated by the method of Hugo Aebi as given by Colowick et al. [26]. GSH peroxidase was determined by the method of Paglia and Valentine [27].

\subsubsection{Xanthine Oxidase Activity}

Tissue xanthine oxidase (XO) activity was measured spectrophotometrically by the formation of uric acid from xanthine through the increase in absorbance at $293 \mathrm{~nm}$ [28].

\subsubsection{Nitric Oxide Level}

The nitric oxide (NO) was estimated by the method of Lepoivre et al. [29].

\subsubsection{Myeloperoxidase Activity (MPO)}

MPO activity was measured in tissues in a procedure similar to that documented by Hillegas et al. [30].

1) Renal Histopathology

The kidney was fixed in 10\% neutral-buffered formalin solution, embedded in paraffin, and was used for histopathological examination. Sections of $5 \mu \mathrm{m}$ thickness were cut on a microtome and taken on glass slides coated with albumin. The hematoxyline-stained sections were stained with eosin for $2 \mathrm{~min}$ and were then quickly passed through ascending grades of alcohol, cleaned in xylene and mounted on Canada Balsam. The stained sections were examined under Olympus BX40 photomicroscope and photographed, to determine histopathological changes. A minimum of 10 fields for each kidney slide were examined and assigned for severity of changes using scores on a scale of none (-), mild (+), moderate (++), and severe (+++) damage [31].

2) Statistical Analysis [32]

Data were expressed as means with their corresponding standard deviations (SD). One way analysis of variance (ANOVA or F-test) was used to compare more than two means. Then the data were subjected to least significant difference (LSD) test. 


\section{Results}

\subsection{Effect of Sitaglipten on Renal Function (Table 1, Figure 2, Figure 3 \& Figure 4)}

Diabetic animals that underwent renal I/R exhibited significant increase in the serum concentrations of urea nitrogen and creatinine, as compared to I/R animals, suggesting a significant degree of glomerular dysfunction mediated by diabetes. Pretreatment of rats with sitaglipten $(10 \mathrm{mcg} / \mathrm{kg})$ produced, a significant reduction in the serum levels of these parameters as compared to DM + I/R group (Table 1, Figure 2, Figure 3 \& Figure 4).

\subsection{Effect of Sitaglipten on Lipid Peroxidation (Table 2, Figures 5, 6, 7, 8, 9) and Antioxidant Enzymes (Table 3, Figures 10, 11, 12, 13)}

The serum TNF- $\alpha$ level was significantly increased in the I/R control as compared to normal control group. In $\mathrm{DM}+\mathrm{I} / \mathrm{R}$ rats, serum TNF- $\alpha$ level was significantly higher as compared to I/R control. Sitaglipten treated group had significantly lower serum TNF- $\alpha$ level as compared to the DM + I/R control group (Table 2, Figure 5).

The renal tissue MDA content in the normal as well as in diabetic group was elevated after induction of I/R injury, compared to normal control group. However, sitaglipten treated group, significantly decreased the I/R-induced elevation in renal MDA level as compared to DM + I/R group (Table 2, Figure 6).

Table 1. Effect of oral administration of sitaglipten on blood urea nitrogen (BUN), creatinine and serum glucose levels in diabetic ischemic reperfused rats.

\begin{tabular}{cccc}
\hline Parameters group studied $(\mathrm{n}=10)$ & BUN $(\mathrm{mg} / \mathrm{dl})$ & Creatinine $(\mathrm{mg} / \mathrm{dl})$ & Serum glucose $(\mathrm{mg} / \mathrm{dl})$ \\
\hline Normal control gp. & $24.1^{\text {bcd }} \pm 1.7$ & $0.32^{\text {bcd }} \pm 0.067$ & $98.1^{\text {bd }} \pm 11.29$ \\
Diabetic gp. & $30.3^{\text {acde }} \pm 1.7$ & $0.64^{\text {acde }} \pm 0.084$ & $474.6^{\text {acde }} \pm 16.94$ \\
Ischemic reperfused (IR) gp. & $34.8^{\text {abde }} \pm 2.2$ & $1.21^{\text {abde }} \pm 0.035$ & $103.6^{\text {bd }} \pm 2.30$ \\
Diabetic+ I/R gp. & $48.9^{\text {abce }} \pm 6.0$ & $2.56^{\text {abce }} \pm 0.13$ & $495^{\text {bbce }} \pm 22.16$ \\
Sitaglipten treated (Diabetic+I/R) gp. & $25.5^{\text {bcd }} \pm 1.4$ & $0.33^{\text {bcd }} \pm 0.24$ & $100^{\text {bd }} \pm 12.29$ \\
F (p) & $102.513^{*}(<0.001)$ & $503.879^{*}(<0.001)$ & $2088.216^{*}(<0.001)$ \\
LSD (5\%) & 2.788 & 0.117 & 13.034 \\
\hline
\end{tabular}

a: Significant with normal control group; b: significant with diabetic group; c: Significant with ischemic reperfused (IR) group; d: Significant with diabetic + I/R group; e: Significant with Sitaglipten treated group.

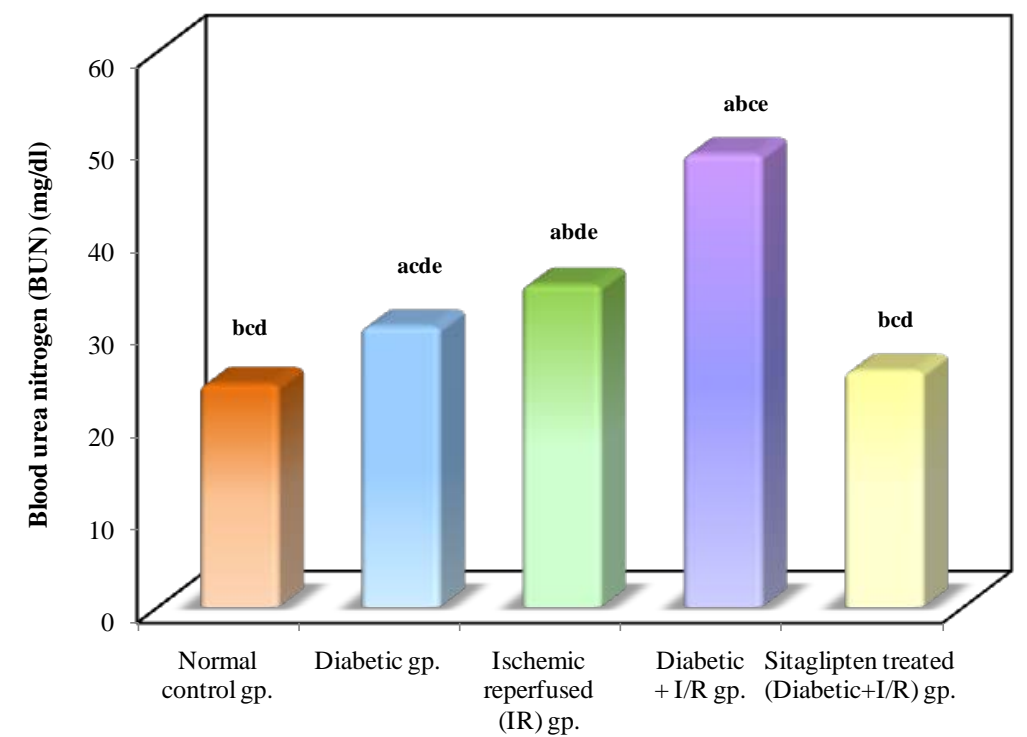

Figure 2. Comparison between the different studied groups according to BUN. 


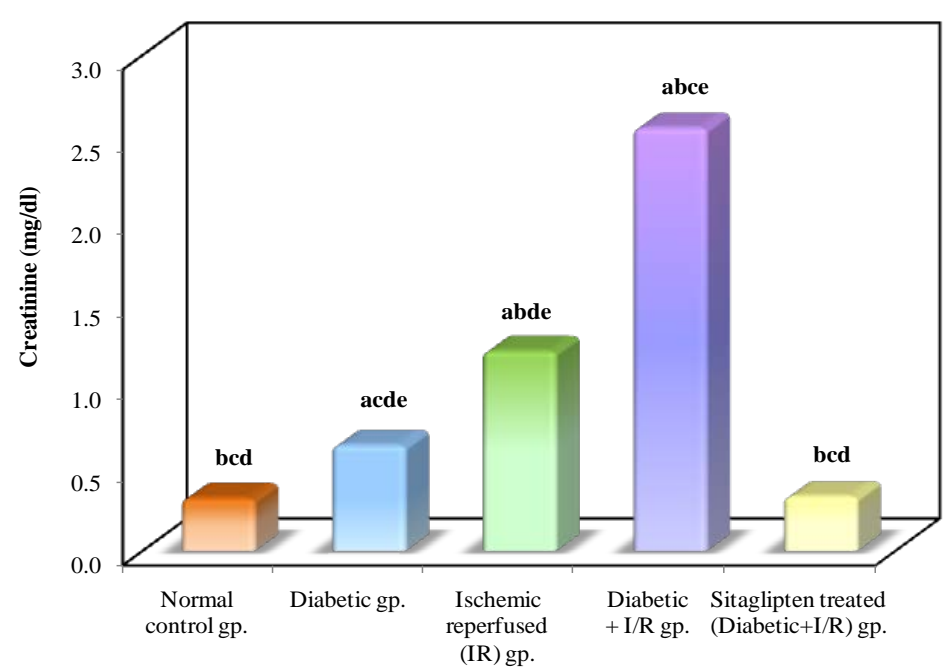

Figure 3. Comparison between the different studied groups according to creatinine.

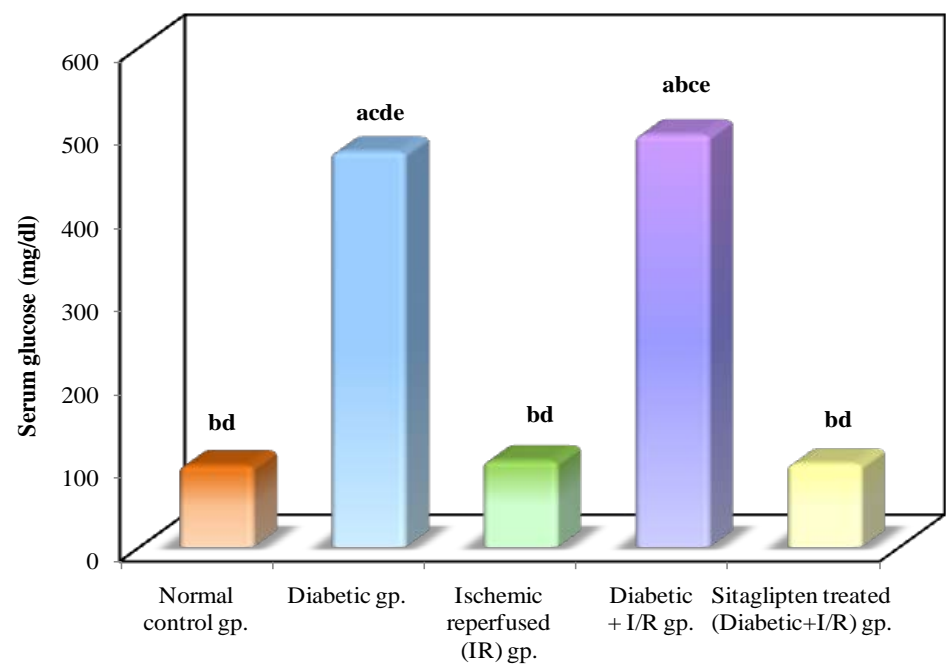

Figure 4. Comparison between the different studied groups according to serum glucose.

Table 2. Effect of oral administration of sitaglipten on serum tumor necrosis factor-alpha (TNF- $\alpha$ ), malondialdehyde (MDA), xanthine oxidase (XO) , nitric oxide (NO) and Myeloperoxidase activity (MPO) in diabetic ischemic reperfused rats.

\begin{tabular}{cccccc}
\hline \multirow{2}{*}{$\begin{array}{c}\text { Parameters group studied } \\
(\mathrm{n}=10)\end{array}$} & \multicolumn{5}{c}{ Renal tissue homogenate } \\
\cline { 2 - 6 } TNF- $\boldsymbol{\alpha}(\mathbf{n g} / \mathbf{m l})$ & MDA $(\mathbf{n m o l} / \mathbf{g})$ & $\mathbf{X O}(\mathbf{U} / \mathbf{g})$ & $\mathbf{N O}(\boldsymbol{\mu m o l} / \mathbf{g})$ & $\mathbf{M P O}(\mathbf{U} / \mathbf{g})$ \\
\hline Normal control gp. & $5.35^{\text {bcde }} \pm 0.43$ & $1.2^{\text {bcde }} \pm 0.15$ & $1.29^{\text {bcd }} \pm 0.05$ & $0.6^{\text {bcd }} \pm 0.03$ & $2.1^{\text {bcd }} \pm 0.05$ \\
Diabetic gp. & $17.78^{\text {acde }} \pm 0.99$ & $3.7^{\text {acde }} \pm 0.41$ & $1.97^{\text {acde }} \pm 0.08$ & $0.8^{\text {acde }} \pm 0.02$ & $3.7^{\text {acde }} \pm 0.51$ \\
Ischemic reperfused (IR) gp. & $19.47^{\text {abde }} \pm 0.82$ & $4.8^{\text {abde }} \pm 0.5$ & $2.1^{\text {abde }} \pm 0.05$ & $0.9^{\text {abde }} \pm 0.025$ & $6.6^{\text {abde }} \pm 0.27$ \\
Diabetic + I/R gp. & $29.15^{\text {abce }} \pm 0.65$ & $6.6^{\text {abce }} \pm 0.27$ & $2.3^{\text {abce }} \pm 0.03$ & $1.3^{\text {abce }} \pm 0.09$ & $8.7^{\text {abce }} \pm 0.41$ \\
Sitaglipten treated (Diabetic + I/R) gp. & $6.52^{\text {abcd }} \pm 0.72$ & $1.7^{\text {abcd }} \pm 0.3$ & $1.3^{\text {bcd }} \pm 0.09$ & $0.6^{\text {bcd }} \pm 0.04$ & $2.3^{\text {bcd }} \pm 0.41$ \\
F (p) & $1758.387^{*}(<0.001)$ & $410.522^{*}(<0.001)$ & $538.407^{*}(<0.001)$ & $356.989^{*}(<0.001)$ & $616.495^{*}(<0.001)$ \\
LSD (5\%) & 0.667 & 0.311 & 0.057 & 0.040 & 0.327 \\
\hline
\end{tabular}

a: Significant with normal control group; b: significant with diabetic group; c: Significant with ischemic reperfused (IR) group; d: Significant with diabetic + I/R group; e: Significant with Sitaglipten treated group. 


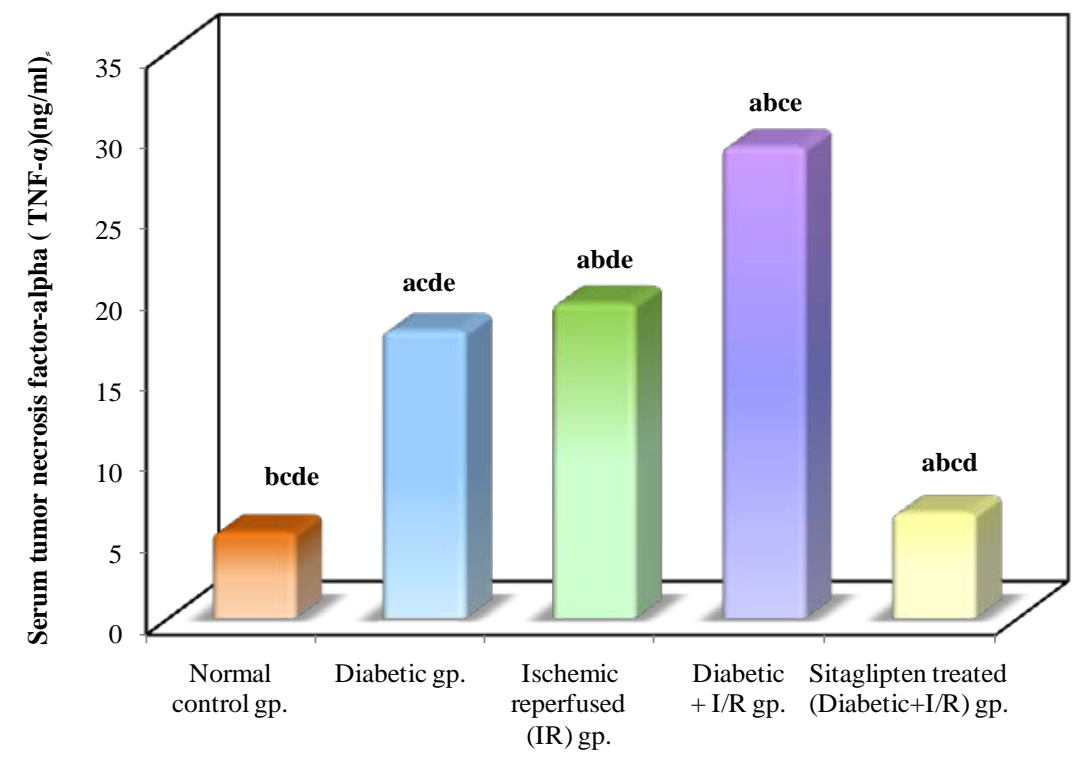

Figure 5. Comparison between the different studied groups according to TNF- $\alpha$.

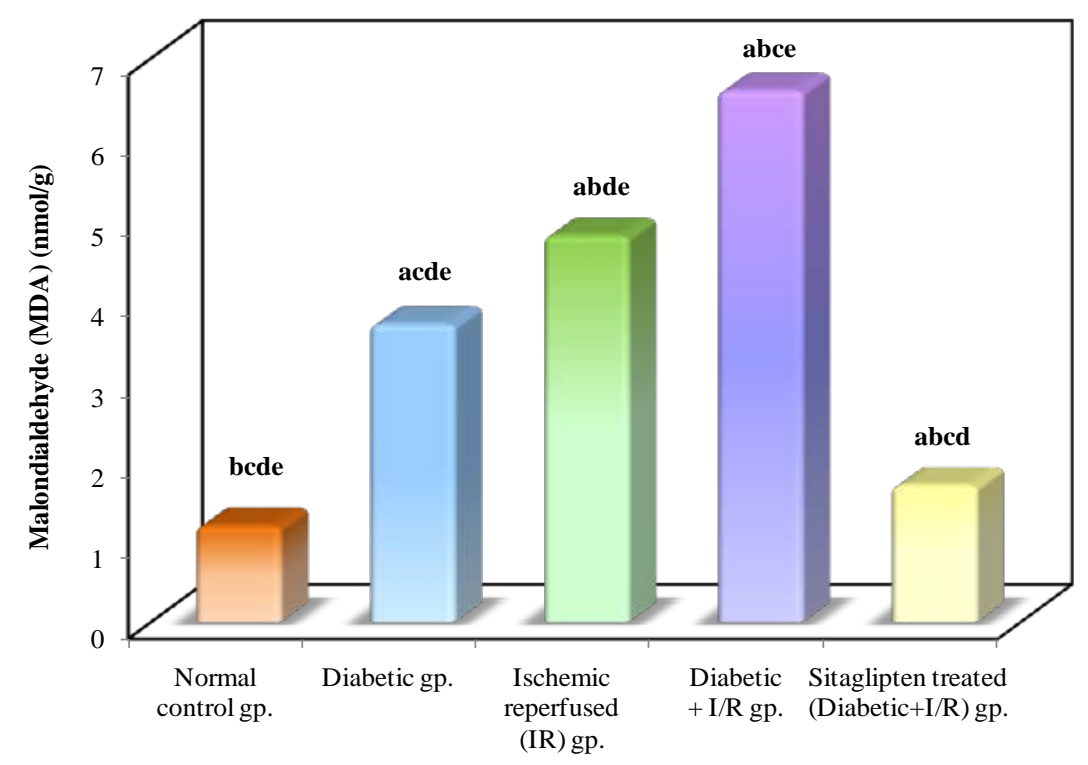

Figure 6. Comparison between the different studied groups according to MDA.

The XO activity was increased in $\mathrm{I} / \mathrm{R}$ and $\mathrm{DM}+\mathrm{I} / \mathrm{R}$ groups as compared to the normal control group. The XO activity was normalized by treatment with sitaglipten compared to DM + I/R (Table 2, Figure 7).

The levels of NO were increased in I/R and DM + I/R groups as compared to normal control group. Sitaglipten treated group demonstrated a significant decrease in NO level as compared to DM + I/R group (Table 2, Figure 8).

Myeloperoxidase (MPO) activity, which is accepted as an indicator of neutrophil infiltration, was significantly higher in the kidney tissue of the $\mathrm{DM}+\mathrm{I} / \mathrm{R}$ group than that of the I/R group. On the other hand, sitaglipten treated group significantly decreased renal tissue MPO level compared to DM + I/R (Table 2, Figure 9).

As regards the antioxidant enzyme activity: Diabetic animals that underwent renal I/R exhibited significant decrease in the SOD activity as compared to I/R animals. However, the activity of SOD in renal tissue was increased in the group pretreated with sitaglipten, as compared to the DM + I/R (Table 3, Figure 10). The catalase (CAT) activity of DM + I/R group was decreased in comparison with I/R group, whereas it was higher in the group 


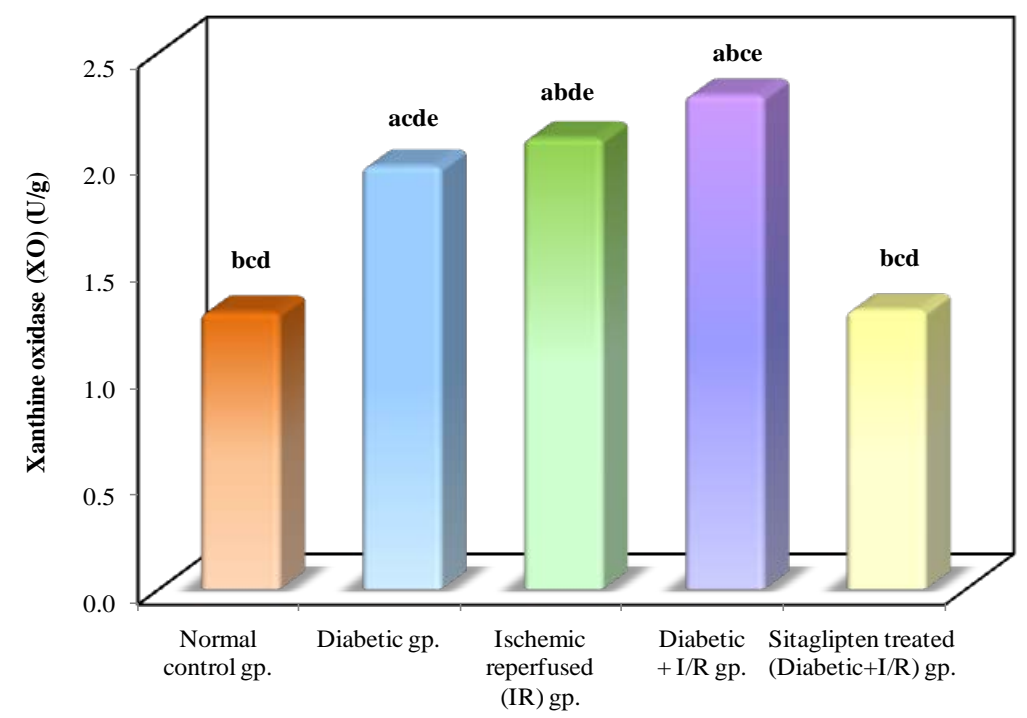

Figure 7. Comparison between the different studied groups according to XO.

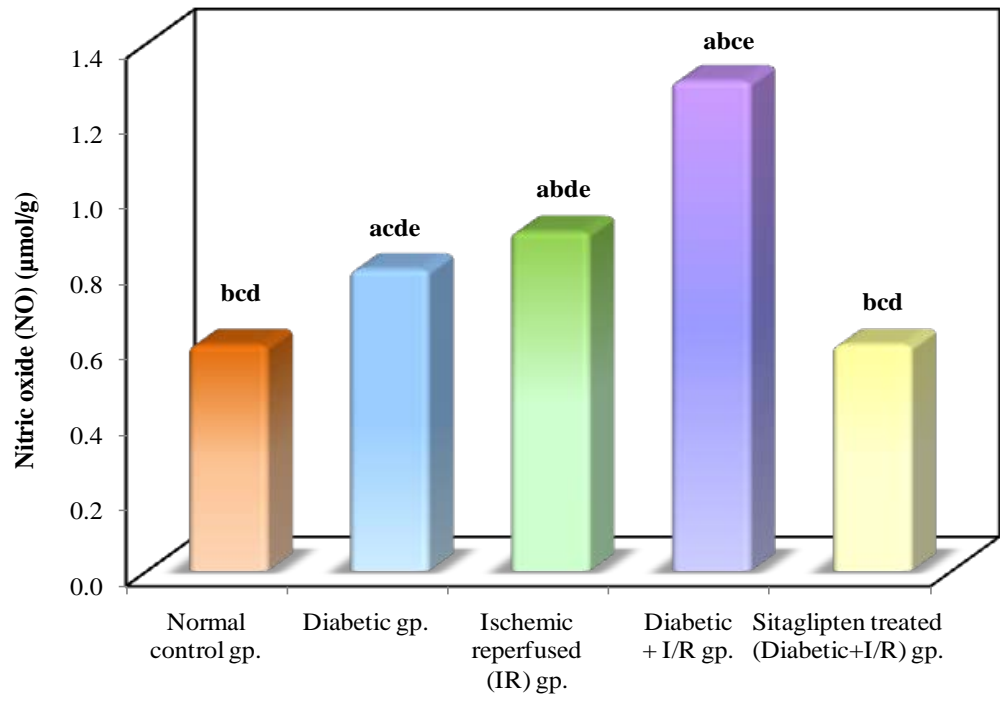

Figure 8. Comparison between the different studied groups according to NO.

Table 3. Effect of oral administration of sitaglipten on superoxide dismutase (SOD), catalase (CAT), reduced glutathione (GSH) and glutathione peroxidase (GSHPx) in diabetic ischemic reperfused rats.

\begin{tabular}{ccccc}
\hline \multirow{2}{*}{ Parameters group studied (n= 10) } & \multicolumn{4}{c}{ Renal tissue homogenate } \\
\cline { 2 - 5 } & $\mathbf{S O D}(\mathbf{U} / \mathbf{g}$ protein) & CAT $(\mathbf{U} / \mathbf{g})$ & $\mathbf{G S H}(\boldsymbol{\mu m o l} / \mathbf{g})$ & $\mathbf{G S H P x}(\mathbf{U} / \mathbf{g})$ \\
Normal control gp. & $5.9^{\mathrm{bcd}} \pm 0.2$ & $1.9^{\mathrm{bcde}} \pm 0.1$ & $37.44^{\mathrm{bcd}} \pm 3.09$ & $1.5^{\text {bcde }} \pm 0.05$ \\
Diabetic gp. & $4.21^{\text {acde }} \pm 0.3$ & $1.0^{\text {acde }} \pm 0.07$ & $29.8^{\text {acde }} \pm 1.08$ & $0.9^{\text {acde }} \pm 0.02$ \\
Ischemic reperfused (IR) gp. & $3.6^{\text {abde }} \pm 0.1$ & $0.9^{\text {abde }} \pm 0.08$ & $24.67^{\text {abde }} \pm 2.31$ & $0.7^{\text {abde }} \pm 0.02$ \\
Diabetic + I/R gp. & $2.9^{\text {abce }} \pm 0.2$ & $0.4^{\text {abce }} \pm 0.09$ & $21.5^{\text {acbe }} \pm 1.7$ & $0.4^{\text {abce }} \pm 0.02$ \\
Sitaglipten treated (Diabetic + I/R) gp. & $5.7^{\text {bcd }} \pm 0.3$ & $1.8^{\text {abcd }} \pm 0.1$ & $38.3^{\text {abd }} \pm 1.3$ & $1.4^{\text {abcd }} \pm 0.04$ \\
F (p) & $316.985^{*}(<0.001)$ & $513.959^{*}(<0.001)$ & $135.937^{*}(<0.001)$ & $2047.170^{*}(<0.001)$ \\
LSD (5\%) & 0.208 & 0.080 & 1.817 & 0.028 \\
\hline
\end{tabular}

a: Significant with normal control group; b: significant with diabetic group; c: Significant with ischemic reperfused (IR) group; d: Significant with diabetic + I/R group; e: Significant with Sitaglipten treated group. 


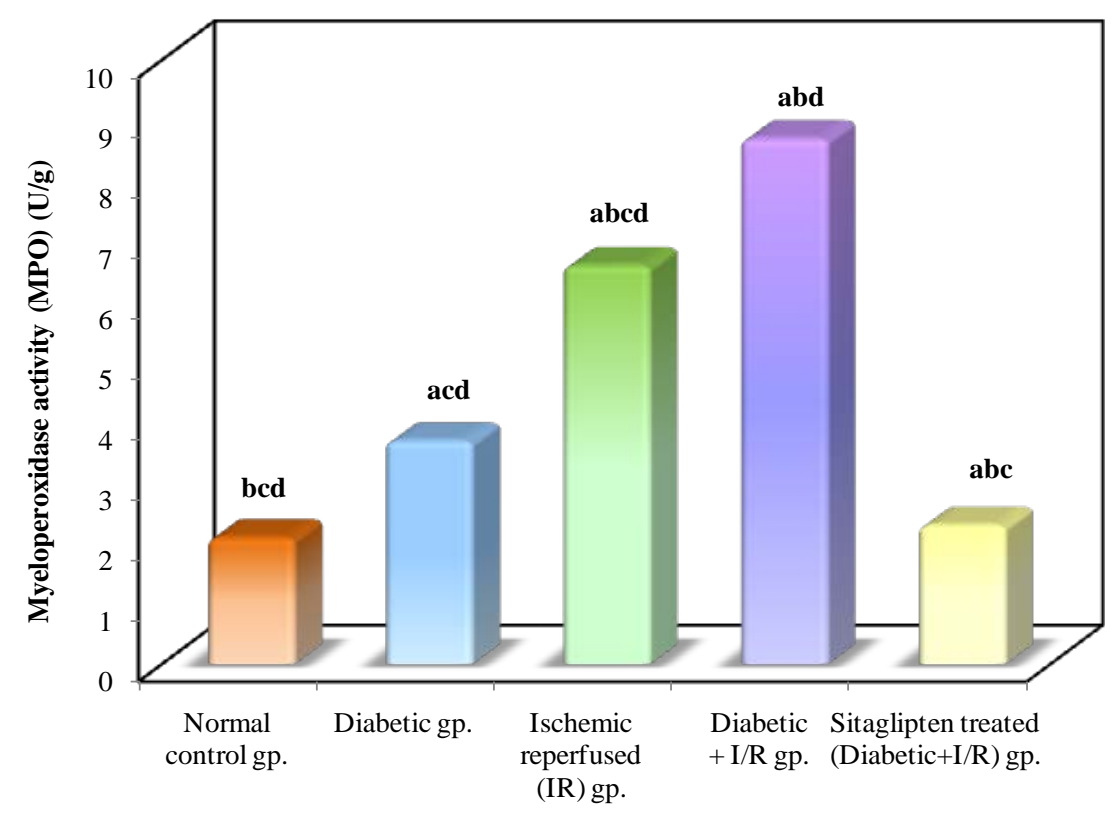

Figure 9. Comparison between the different studied groups according to MPO.

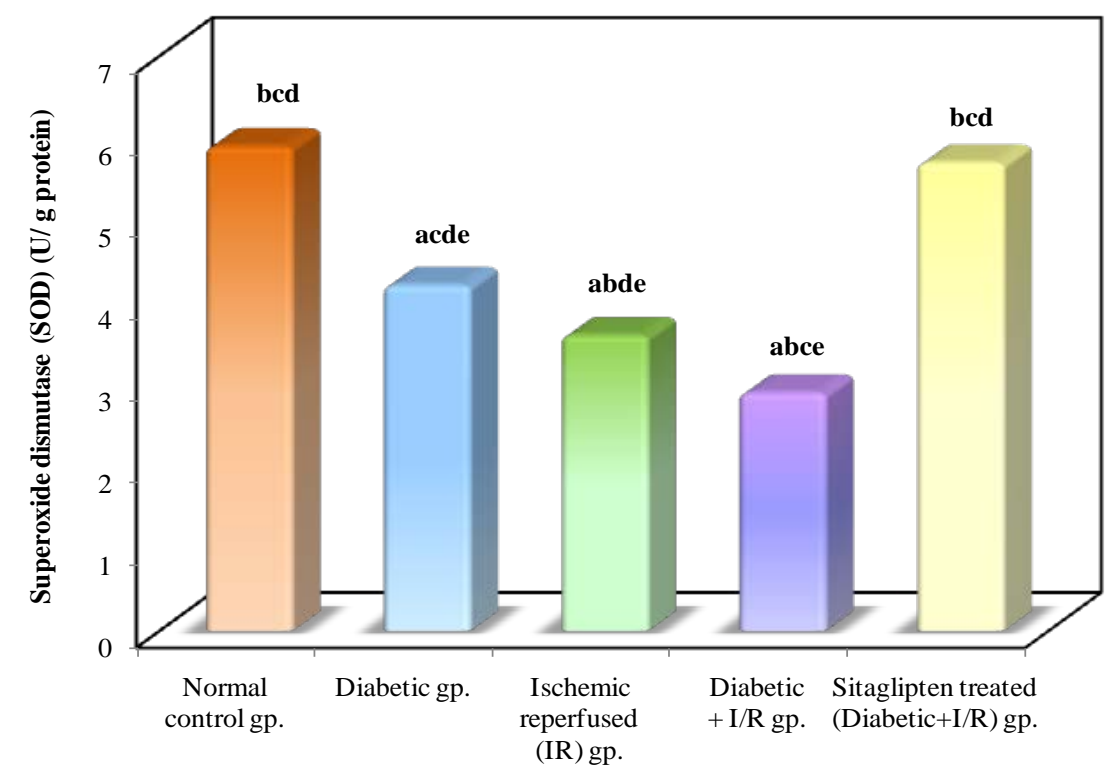

Figure 10. Comparison between the different studied groups according to SOD.

pretreated with sitaglipten than in the DM + I/R group (Table 3, Figure 11).

In I/R diabetic rats, there was a significant decrease in renal tissue GSH and GSHPx level when compared to normal control group, while in the sitaglipten-treated group, renal GSH, and GSHPx content were found to be preserved (Table 3, Figure 12 \& Figure 13).

\subsection{Effect of Sitaglipten on Renal Histology}

The histopathological changes were shown in (Figure 14). The kidneys of untreated I/R rats showed tubular cell swelling, interstitial edema, tubular dilatation, hyaline casts, and moderate-to-severe necrosis. Treatment with sitaglipten $(10 \mathrm{mcg} / \mathrm{kg})$ preserved the normal morphology of the kidney, and shows normal glomeruli and normal tubular cells. 


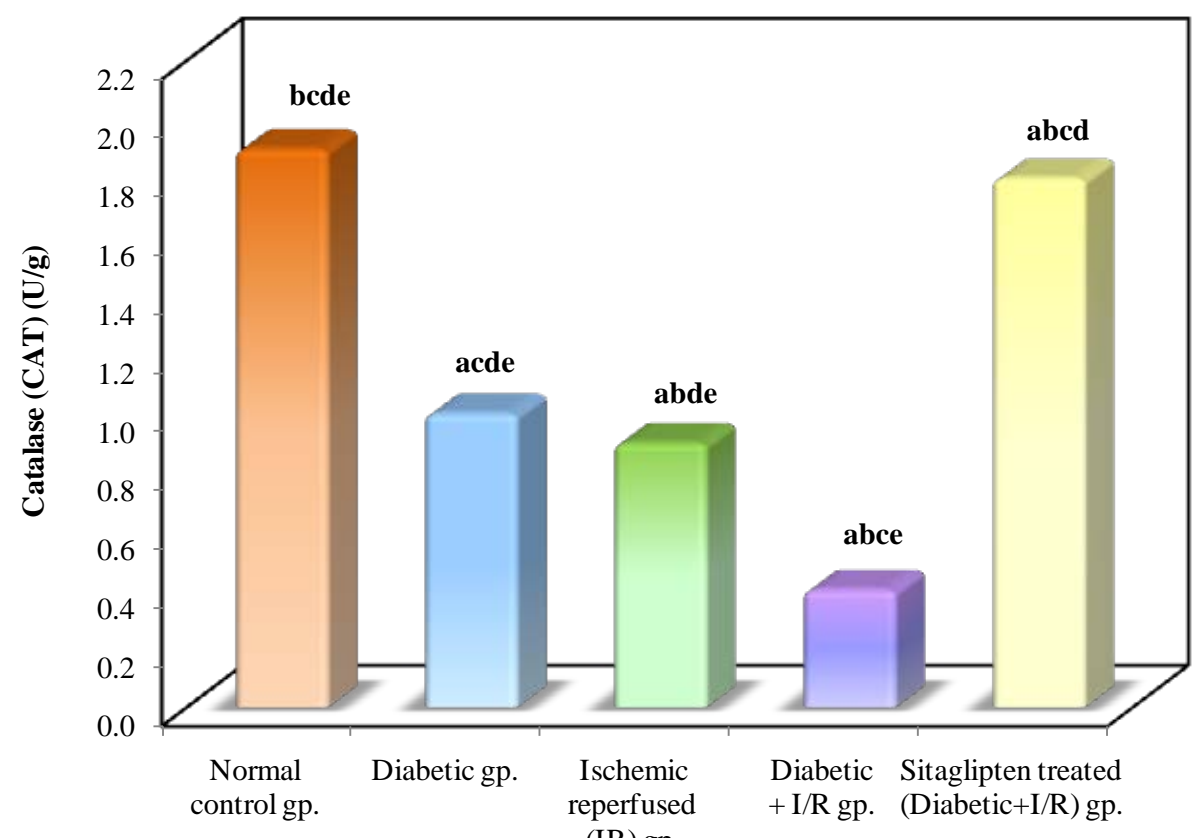

(IR) gp.

Figure 11. Comparison between the different studied groups according to CAT.

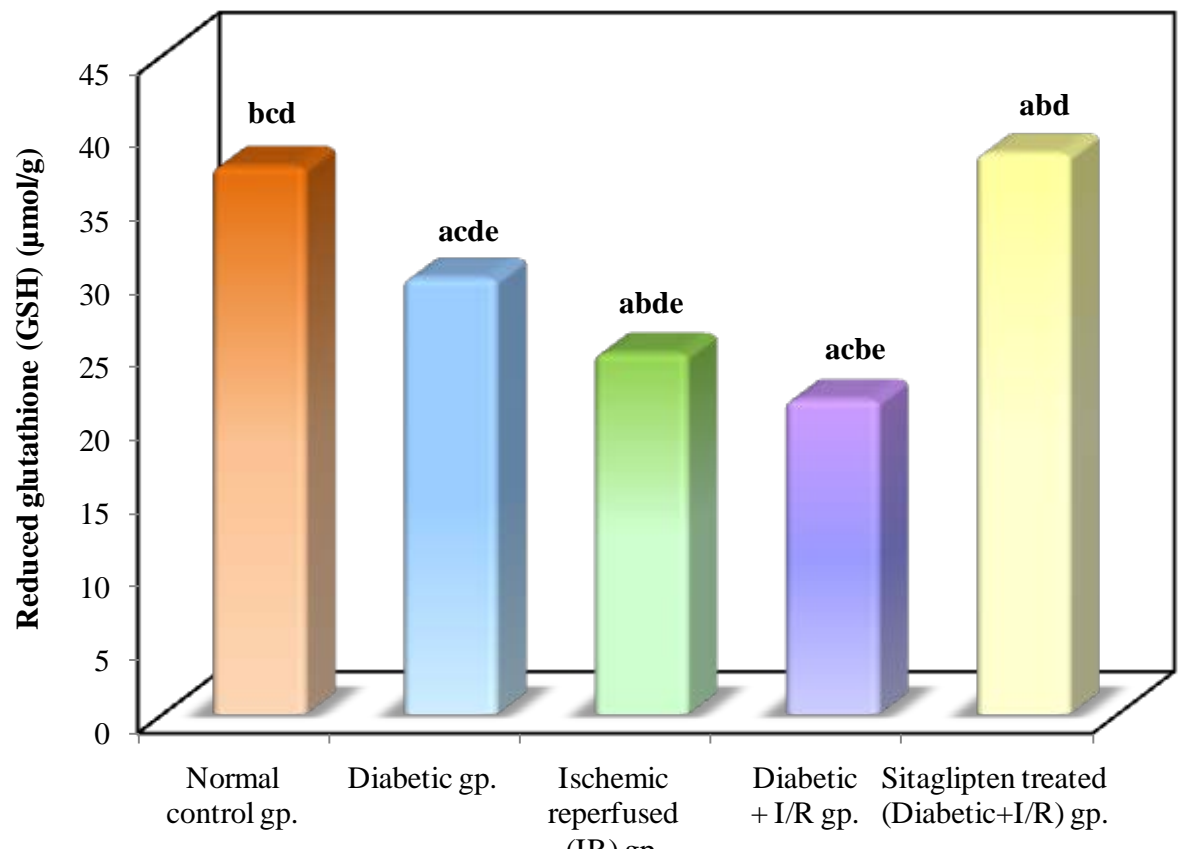

(IR) gp.

Figure 12. Comparison between the different studied groups according to GSH.

\section{Discussion}

Diabetes mellitus (DM) especially type 2 causes organ dysfunction and increases the sensitivity of organs to damages. In the present study, we tested the hypothesis that DM and hyperglycaemia render the kidney more susceptible to ischemic injury and examined the effect of renal ischemia for $30 \mathrm{~min}$ on renal functions, histological damage, proinflammatory cytokines TNF- $\alpha$ as well as oxidant markers in STZ induced type 2 DM. Also, the present study examined the possible role of sitaglipten in these changes. 


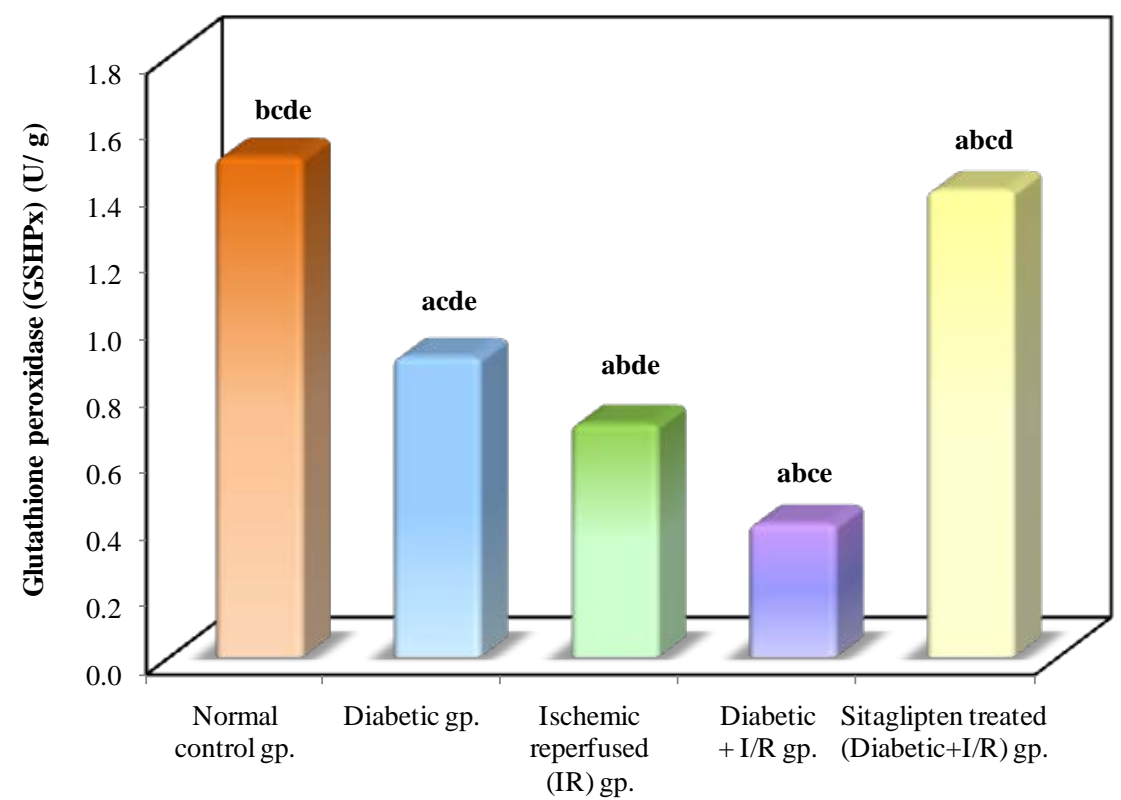

Figure 13. Comparison between the different studied groups according to GSHPx.

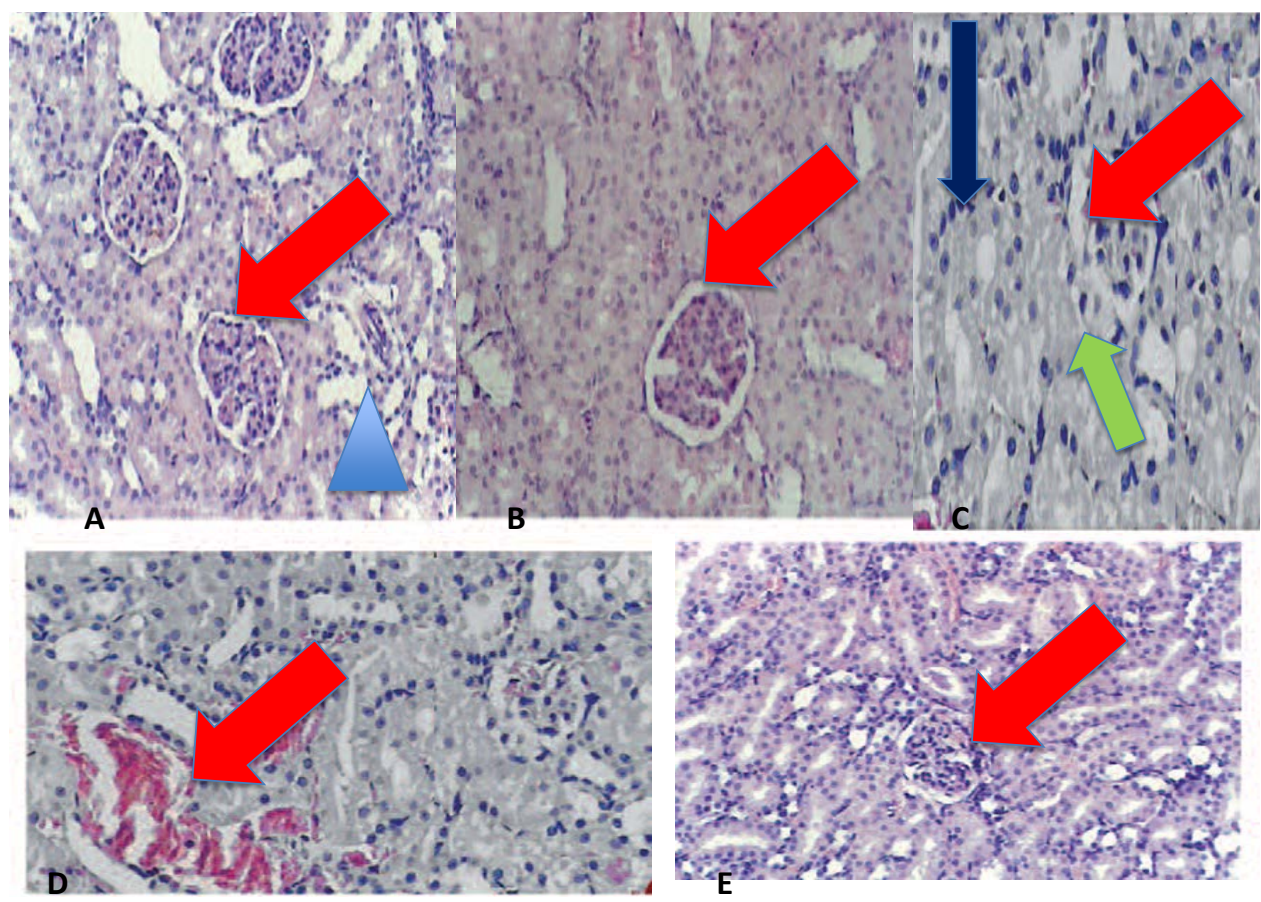

Figure 14. Sitaglipten improves renal tissue ischemia. Sections were stained with hematoxylin and eosin. (A) Section from normal kidney demonstrates the presence of 3 glomeruli exhibiting round configuration, normal cellularity (red arrow), and normal tubules with healthy lining epithelium (blue arrow head). (10×) (B) Section from diabetic kidney shows thickening of the glomerular capillary basement membrane. $(10 \times)(C)$ Section from kidney subjected to I/R shows golmerular atrophy (red arrow), influx of inflammatory cells (blue arrow), and necrosis of the epithelial lining of renal tubules (green arrow). (20×) (D) Section from diabetic kidney subjected to I/R Shows marked vascular congestion (red arrow), atrophy and necrosis of the tubular lining epithelium. (20×) (E) Section from diabetic kidney subjected to I/R and treated with sitaglipten (10 $\mathrm{mcg} / \mathrm{kg}$ ) shows that sitaglipten preserved the normal morphology of the kidney, normal glomeruli and normal tubular cells. $(10 \times)$ 
Diabetic rats in the present study showed significant increase in the serum blood glucose, creatinine, blood urea nitrogen, tumor necrosis factor-alpha (TNF- $\alpha$ ), malondialdehyde (MDA), xanthine oxidase (XO), nitric oxide (NO) and myeloperoxidase activity (MPO). These markers became significantly higher in diabetic rats after the episode of ischemia. At the same time, there is a negative correlation between sitaglipten and these parameters. These findings suggest the possible role of proinflammatory cytokines; TNF- $\alpha$ and oxidative markers in pathogenesis of ischemic injury in diabetic kidney.

Regarding the increased creatinine and BUN in this study, which are in agreement with several studies which reported that, in experimentally diabetic rats, there is a significant increase in serum creatinine levels ascompared to normoglycemic ones and this is considered as an indicator of deteriorated renal function [33]-[35]. Hyperglycaemia is most probably a contributing factor in the development of renal ischemia. Shortage of insulin could also be involved in the increased sensitivity to I/R. Secondary effects of hyperglycemia such as formation of advanced glycosylated end products (AGEs), increased oxidative stress, hemodynamic alterations, and formation of NO could also be involved.

In addition, our results confirmed the findings of Yousef et al. [36] who found that combination of renal ischemia with DM raised serum creatinine more than did DM alone suggesting significant impairment of glomerular function.

In consistence with renal function impairment, histopathological examination revealed significant increase in acute tubular necrosis score in diabetic ischemic rats with characteristic morphological changes, such as tubular cell swelling, tubular dilatation, necrosis of epithelium, and interstitial edema. In contrast, sections of the sitaglipten pretreated kidneys demonstrated architectural and cytological preservation of structure.

The present study showed significant rise in serum TNF- $\alpha$ level in diabetic non-ischemic, ischemic, and diabetic ischemic rats, as compared to normal control rats, but the marked rise was found in diabetic ischemic rats. These findings are in consistent with many studies that demonstrated significant rise in serum TNF- $\alpha$ level in renal I/R injury [37]-[39].The increased TNF- $\alpha$ in ischemic diabetic rats may result from constitutive overproduction by adipose tissue in type 2 diabetes, the effects of hyperglycemia and AGEs and increased generation of ROS in renal I/R injury and DM [40] [41]. Hyperglycemia induced oxidative stress, along with AGEs and products of lipid peroxidation, possibly serves as activators of transcription factors, leading to induction of gene expression of pro-inflammatory cytokines and release of many inflammatory cytokines as TNF- $\alpha$ and IL-6 through NF- $\mathrm{BB}$ [42]. TNF- $\alpha$ can induce renal injury via induction of apoptosis and necrotic cell death, alterations of intra-glomerular blood flow and glomerular filtration rate as a result of the hemodynamic imbalance between vasoconstrictive and vasodilator mediators, alterations of endothelial permeability, as well as alterations of the barrier function of the glomerular capillary wall leading to enhanced albumin permeability [43]. At the molecular level TNF- $\alpha$ augments the release of many inflammatory factors from renal mesangial cells [44] [45].

This may confirm our results in which we found that there is a significant positive correlation between serum TNF- $\alpha$ and renal tissue content of MDA and XO.

Another point of interest in the present study was to investigate the involvement of NO in development of renal I/R injury in DM. NO was significantly elevated in renal tissue in diabetic ischemic rats. This result coupe with many authors who documented that iNOS is activated in the kidney of rats, soon after the induction of diabetes, suggesting its involvement in the increased production of NO observed immediately after the onset of diabetes [33] [46].

The NO system may be involved in the increased sensitivity to I/R in DM. There is evidence for increased NO-production in the STZ-DM kidney, the reaction of NO with $\mathrm{O}_{2}$ results in peroxynitrite formation, a potent and aggressive cellular oxidant and causes the formation of 3-nitro-l-tyrosine. Nitrite/nitrate levels, as the end products of NO conversion, were increased in blood plasma and aortic tissue in diabetic animals as compared to nondiabetic ones [46] which was confirmed by elevated NO level in our study.

Infiltration of inflammatory cells is one of the main features of renal $\mathrm{I} / \mathrm{R}$ injury in diabetic rats. The infiltrate mainly consisted of cells identified as macrophages/monocytes and T-lymphocytes [47]. This study demonstrated high renal MPO activity after induction of I/R in diabetic rats. This reflects high-leukocyte infiltration in the renal tissue. The neutrophils play a major role in oxidant injury via the mechanisms such as the action of nicotinamide adenine dinucleotide phosphate (NADPH) oxidase or MPO system. HOCl which is produced largely from stimulated neutrophils by MPO activity, causes oxidation of other molecules such as proteins, amino acids, carbohydrates, nucleic acids, and lipids expanding renal tissue damage [48]. 
Sitaglipten in this study reduced the oxidative stress and the biomarkers of the inflammation which are determinant factors in the course of renal disease. Treatment with sitaglipten prevented renal I/R-induced lipid peroxidation and protected the kidneys from severe attenuation of antioxidant enzymes activity in rats exposed to the renal I/R. In addition, it improved the functional renal parameters as BUN and creatinine. The histological specimens has proved that sitaglipten treated rats was protected against renal I/R in diabetes.

Several mechanisms might be responsible for the renoprotective effects of sitaglipten against renal I/R. First, the restoration of normoglycemia, because glucose metabolism is stimulated over fatty acid metabolism, which is more efficient with respect to oxygen consumption for adenosine triphosphate production and which might therefore reduce oxygen demand. An increased acute sensitivity to ischemia has been demonstrated when blood glucose level was raised by dextrose infusion or intraperitoneal glucose injection in combination with renal $\mathrm{I} / \mathrm{R}$ in both rats and dogs [49]. In our study, glucose controlled by sitaglipten pretreatment could has a protective effect against renal $\mathrm{I} / \mathrm{R}$ in type $2 \mathrm{DM}$.

Additionally, sitaglipten might reduce apoptosis and oxidative stress. Ferreira et al. demonstrated that the activity of the antioxidant enzymes SOD and catalase were higher in animals treated with sitaglipten and nuclear oxidative stress was reduced. In addition, they demonstrated beneficial effects of sitagliptin on metabolic profile and reduction in inflammatory markers, as well as amelioration of fibrosis, vacuolization, and congestion in endocrine pancreas and preservation of pancreatic islets [50]. Our results agree with those performed by others, which have been suggesting an antioxidant and anti-inflammatory effect of incretin modulators, due to attenuation of the deleterious effects of AGEs-RAGE-oxidative stress axis and to protection against the cytokine- induced apoptosis and necrosis [51]-[53].

\section{Conclusion}

In conclusion, type 2 diabetes provoked an exaggerated renal I/R injury in STZ treated rats. Sitaglipten treatment attenuated acute I/R-induced renal injury in diabetic rats modifying the oxidative stress and the inflammation processes. Therefore, the protection afforded reflects both improved glucose metabolism as well as the antiinflammatory, anti-oxidant, anti-fibrotic, and anti-apoptotic effects.

\section{Acknowledgements}

The authors gratefully acknowledge the grant of center of scientific research and revival of Islamic heritage No (43209012).

\section{References}

[1] Maisonneuve, P., Agodoa, L., Gellert, R., et al. (2000) Distribution of Primary Renal Diseases Leading to End-Stage Renal Failure in the United States, Europe, and Australia/New Zealand: Results from an International Comparative Study. American Journal of Kidney Disease, 35, 157-165. http://dx.doi.org/10.1016/S0272-6386(00)70316-7

[2] Hokama, J.Y., Ritter, L.S., Gorman, G.D., Cimetta, A.D., Copeland, J.G. and McDonagh, P.F. (2000) Diabetes Enhances Leukocyte Accumulation in the Coronary Microcirculation Early in Reperfusion Following Ischemia. Journal of Diabetes Complication, 14, 96-107. http://dx.doi.org/10.1016/S1056-8727(00)00068-4

[3] Yellon, D.M. and Baxter, G.F. (2000) Protecting the Ischaemic and Reperfused Myocardium in Acute Myocardial Infarction: Distant Dream or Near Reality? Heart, 83, 381-387. http://dx.doi.org/10.1136/heart.83.4.381

[4] Yokoyama, H., Okudaira, M., Otani, T., et al. (2000) Higher Incidence of Diabetic Nephropathy in Type 2 than in Type 1 Diabetes in Early-Onset Diabetes in Japan. Kidney International, 58, 302-311. http://dx.doi.org/10.1046/j.1523-1755.2000.00166.x

[5] Basireddy, M., Isbell, T.S., Teng, X., Patel, R.P. and Agarwal, A. (2006) Effects of Sodium Nitrite on Ischemia-Reperfusion Injury in the Rat Kidney. American Journal of Physiology-Renal Physiology, 290, F779-F786. http://dx.doi.org/10.1152/ajprenal.00334.2005

[6] Ysebaert, D.K., De-Greef, K.E., De-Beuf, A., et al. (2004) T Cells as Mediators in Renal Ischemia/Reperfusion Injury. Kidney International, 66, 491-496. http://dx.doi.org/10.1111/j.1523-1755.2004.761 4.x

[7] Altunoluk, B., Soylemez, H., Oguz, F., Turkmen, E. and Fadillioglu, E. (2006) An Angiotensin-Converting Enzyme Inhibitor, Zofenopril, Prevents Renal Ischemia/Reperfusion Injury in Rats. Annals of Clinical \& Laboratory Science, 36, 326-332.

[8] Bolen, S., Feldman, L., Vassy, J., et al. (2007) Systematic Review: Comparative Effectiveness and Safety of Oral Me- 
dications for Type 2 Diabetes Mellitus. Annals of Internal Medicine, 147, 386-399.

[9] Taylor, S.I., Accili, D. and Imai, Y. (1994) Insulin Resistance or Insulin Deficiency. Which Is the Primary Cause of NIDDM? Diabetes, 43, 735-740. http://dx.doi.org/10.2337/diab.43.6.735

[10] Cavaghan, M.K., Ehrmann, D.A. and Polonsky, K.S. (2000) Interactions between Insulin Resistance and Insulin Secretion in the Development of Glucose Intolerance. Journal of Clinical Investigation, 106, 329-333. http://dx.doi.org/10.1172/JCI10761

[11] Holman, R.R. (2006) Long-Term Efficacy of Sulfonylureas: A United Kingdom Prospective Diabetes Study Perspective. Metabolism, 55, S2-S5. http://dx.doi.org/10.1016/j.metabol.2006.02.006

[12] Stahl, M. and Berger, W. (1999) Higher Incidence of Severe Hypoglycaemia Leading to Hospital Admission in Type 2 Diabetic Patients Treated with Long-Acting versus Short-Acting Sulphonylureas. Diabetic Medicine, 16, 586-590. http://dx.doi.org/10.1046/j.1464-5491.1999.00110.x

[13] Holst, J.J. (1997) Enteroglucagon. Annual Review of Physiology, 59, 257-271. http://dx.doi.org/10.1146/annurev.physiol.59.1.257

[14] MacDonald, P.E., El-Kholy, W., Riedel, M.J., Salapatek, A.M., Light, P.E. and Wheeler, M.B. (2002) The Multiple Actions of GLP-1 on the Process of Glucose-Stimulated Insulin Secretion. Diabetes, 519, S434-S442.

[15] Kieffer, T.J., McIntosh, C.H. and Pederson, R.A. (1995) Degradation of Glucose-Dependent Insulinotropic Polypeptide and Truncated Glucagon-Like Peptide 1 in Vitro and in Vivo by Dipeptidyl Peptidase IV. Endocrinology, 136, 35853596.

[16] Raz, I., Hanefeld, M., Xu, L., Caria, C., Williams-Herman, D. and Khatami, H. (2006) Efficacy and Safety of the Dipeptidyl Peptidase-4 Inhibitor Sitagliptin as Monotherapy in Patients with Type 2 Diabetes Mellitus. Diabetologia, 49, 2564-2571. http://dx.doi.org/10.1007/s00125-006-0416-Z

[17] Rosenstock, J., Baron, M.A., Dejager, S., Mills, D. and Schweizer, A. (2007) Comparison of Vildagliptin and Rosiglitazone Monotherapy in Patients with Type 2 Diabetes: A 24-Week, Double-Blind, Randomized Trial. Diabetes Care, 30, 217-223. http://dx.doi.org/10.2337/dc06-1815

[18] Rosenstock, J., Sankoh, S. and List, J.F. (2008) Glucose-Lowering Activity of the Dipeptidyl Peptidase-4 Inhibitor Saxagliptin in Drug-Naive Patients with Type 2 Diabetes. Diabetes, Obesity and Metabolism, 10, 376-386. http://dx.doi.org/10.1111/j.1463-1326.2008.00876.x

[19] Bose, A.K., Mocanu, M.M., Carr, R.D., Brand, C.L. and Yellon, D.M. (2005) Glucagon-Like Peptide 1 Can Directly Protect the Heart against Ischemia/Reperfusion Injury. Diabetes, 54, 146-151. http://dx.doi.org/10.2337/diabetes.54.1.146

[20] Atsuo, T., Akiko, M.Y., Ryosuke, N., Yuka, S., Masahiko, H. and Masayuki, S. (2009) Antihyperglycemic Effects of ASP8497 in Streptozotocin-Nicotinamide Induced Diabetic Rats: Comparison with Other Dipeptidyl Peptidase-IV Inhibitors. Pharmacological Reports, 61, 899-908. http://dx.doi.org/10.1016/S1734-1140(09)70147-1

[21] Bose, A.K., Mocanu, M.M., Carr, R.D. and Yellon, D.M. (2005) Glucagon Like Peptide-1 Is Protective against Myocardial Ischemia/Reperfusion Injury When Given Either as a Preconditioning Mimetic or at Reperfusion in An Isolated Rat Heart Model. Cardiovascular Drugs and Therapy, 19, 9-11. http://dx.doi.org/10.1007/s10557-005-6892-4

[22] Masiello, P., Broca, C., Gross, R., Roye, M., Manteghetti, M., Hillaire-Buys, D., et al. (1998) Experimental NIDDM: Development of a New Model in Adult Rats Administered Streptozotocin and Nicotinamide. Diabetes, 47, $224-229$. http://dx.doi.org/10.2337/diab.47.2.224

[23] Slater, T.F. and Sawyer, B.C. (1971) The Stimulatory Effects of Carbon Tetrachloride and Other Halogenoalkanes or Peroxidative Reactions in Liver Fractions in Vitro. Biochemical Journal, 123, 805-814.

[24] Moran, M.S., Depierre, J.W. and Mannervik, B. (1979) Levels of Glutathione, Glutathione Reductase and Glutathione S-Transferase Activities in Rat Lung and Liver. Biochimica et Biophysica Acta (BBA), General Subjects, 582, 67-78. http://dx.doi.org/10.1016/0304-4165(79)90289-7

[25] Misra, H.P. and Fridovich, I. (1972) The Role of Superoxide Anion in the Autooxidation of Epinephrine and a Simple Assay of SOD. Journal of Biological Chemistry, 247, 3170-3175.

[26] Aebi, H. (1984) Oxido Reductases Acting on Groups Other Than CHOH: Catalase. In: Colowick, S.P., Kaplan, N.O. and Packer, L., Eds., Methods in Enzymology, Academic Press, London, Vol. 105, 121-125.

[27] Paglia, D.E. and Valentine, W.N. (1967) Studies on the Quantitative and Qualitative Characterization of Erythrocyte Peroxidase. Journal of Laboratory and Clinical Medicine, 2, 158-169.

[28] Prajda, N. and Weber, G. (1975) Malign Transformation-Linked Imbalance: Decreased Xanthine Oxidase Activity in Hepatomas. FEBS Letters, 59, 245-249. http://dx.doi.org/10.1016/0014-5793(75)80385-1

[29] Lepoivre, G., Iwanejko, J., Dembińska-Kieć, A., Pankiewicz, J., Wanat, A., Anna, P., et al. (1998) Determination of Nitrite/Nitrate in Human Biological Material by the Simple Griess Reaction. Clinica Chimica Acta, 274, 177-188. 
http://dx.doi.org/10.1016/S0009-8981(98)00060-6

[30] Wei, H. and Frenkel, K. (1993) Relationship of Oxidative Events and DNA Oxidation in SENCAR Mice to in Vivo Promoting Activity of Phorbol Ester-Type Tumor Promoters. Carcinogenesis, 14, 1195-1201. http://dx.doi.org/10.1093/carcin/14.6.1195

[31] Jablonski, P., Howden, B., Rae, D., Birrel, C., Marshall, V. and Tange, J. (1983) An Experimental Model for Assessment of Renal Recovery from Warm Ischaemia. Transplantation, 35, 198-204. http://dx.doi.org/10.1097/00007890-198303000-00002

[32] Hill, B.A. (1971) Principles of Medical Statistics. 9th Edition, Lancet Limited Publications, London, 147, 383.

[33] Umrani, D.N. and Goyal, R.K. (2003) Fenoldopam Treatment Improves Peripheral Insulin Sensitivity and Renal Function in STZ-Induced Type 2 Diabetic Rats. Clinical and Experimental Hypertension, 25, 221-233. http://dx.doi.org/10.1081/CEH-120020392

[34] Chen, H., Brahmbhatt, S., Gupta, A. and Sharma, A.C. (2005) Duration of Streptozotocin-Induced Diabetes Differentially Affects p38-Mitogen-Activated Protein Kinase (MAPK) Phosphorylation in Renal and Vascular Dysfunction. Cardiovascular Diabetology, 4, 3. http://dx.doi.org/10.1186/1475-2840-4-3

[35] Kuhad, A. and Chopra, K. (2009) Attenuation of Diabetic Nephropathy by Tocotrienol: Involvement of NFkB Signaling Pathway. Life Science, 84, 296-301. http://dx.doi.org/10.1016/j.lfs.2008.12.014

[36] Yousef, W.M., Omar, A.H., Ghanayeem, N.M., Waheed, M.M.A. and Morsey, M.D. (2005) Effect of Some Calcium Channel Blockers in Experimentally Induced Diabetic Nephropathy in Rats. Indocrinology, Metabolism and Diabetes Journal, 14, 39-49.

[37] Şener, G., Tuğtepe, H., Yüksel, M., Çetinel, S., Gedik, N. and Yeğen, B.Ç. (2006) Resveratrol Improves Ischemia/Reperfusion-Induced Oxidative Renal Injury in Rats. Archives of Medical Research, 37, 822-829. http://dx.doi.org/10.1016/j.arcmed.2006.04.003

[38] Tuğtepe, H., Şener, G., Biyikli, N.K., Yüksel, M., Çetinel, S., Gedik, N. and Yeğen, B.Ç. (2007) The Protective Effect of Oxytocin on Renal Ischemia/Reperfusion Injury in Rats. Regulatory Peptides, 140, 101-108. http://dx.doi.org/10.1016/j.regpep.2006.11.026

[39] Satoh, J., Yagihashi, S. and Toyota, T. (2003) The Possible Role of Tumor Necrosis Factor-Alpha in Diabetic Polyneuropathy. Experimental Diabesity Research, 4, 65-71. http://dx.doi.org/10.1155/EDR.2003.65

[40] Bonventre, J.V. and Zuk, A. (2004) Ischemic Acute Renal Failure: An Inflammatory Disease? Kidney International, 66, 480-485. http://dx.doi.org/10.1111/j.1523-1755.2004.761_2.x

[41] Liu, R., Bal, H.S., Desta, T., Behl, Y. and Graves, D.T. (2006) Tumor Necrosis Factor- $\alpha$ Mediates Diabetes-Enhanced Apoptosis of Matrix-Producing Cells and Impairs Diabetic Healing. The American Journal of Clinical Pathology, 168, 757-764. http://dx.doi.org/10.2353/ajpath.2006.050907

[42] Yamagishi, S., Fukami, K., Ueda, S. and Okuda, S. (2007) Molecular Mechanisms of Diabetic Nephropathy and It’s Therapeutic Intervention. Current Drug Targets, 8, 952-959. http://dx.doi.org/10.2174/138945007781386884

[43] Koike, N., Takamura, T. and Kaneko, S. (2007) Induction of Reactive Oxygen Species from Isolated Rat Glomeruli by Protein Kinase C Activation and TNF- $\alpha$ Stimulation, and Effects of a Phosphodiesterase Inhibitor. Life Science, 80, 1721-1728. http://dx.doi.org/10.1016/j.lfs.2007.02.001

[44] Yeboah, M.M., Xue, X., Duan, B., Ochani, M., Tracey, K.J., Susin, M., et al. (2008) Cholinergic Agonists Attenuate Renal Ischemia-Reperfusion Injury in Rats. Kidney International, 74, 62-69. http://dx.doi.org/10.1038/ki.2008.94

[45] Jitendra, D.V., Navin, R.S., Yagnik, S.B. and Nurudin, P.J. (2010) Exaggerated Liver Injury Induced by Renal Ischemia Reperfusion in Diabetes: Effect of Exenatide. The Saudi Journal of Gastroenterology, 16, 174-180. http://dx.doi.org/10.4103/1319-3767.65187

[46] Zheng, L., Du, Y., Miller, C., et al. (2007) Critical Role of Inducible Nitric Oxide Synthase in Degeneration of Retinal Capillaries in Mice with Streptozotocin-Induced Diabetes. Diabetologia, 50, 1987-1996.

[47] Yagmurca, M., Erdogan, H., Iraz, M., Songur, A., Ucar, M. and Fadillioglu, E. (2004) Caffeic Acid Phenethyl Ester as a Protective Agent against Doxorubicin Nephrotoxicity in Rats. Clinica Chimica Acta, 348, 27-34. http://dx.doi.org/10.1016/j.cccn.2004.03.035

[48] Matsuyama, M., Yoshimura, R., Hase, T., Kawahito, Y., Sano, H. and Nakatani, T. (2005) Study of Cyclooxygenase-2 in Renal Ischemia-Reperfusion Injury. Transplantation Proceeding, 37, 370-372. http://dx.doi.org/10.1016/j.transproceed.2004.12.246

[49] Moursi, M., Rising, C.L., Zelenock, G.B. and D’Alecy, L.G. (1997) Dextrose Administration Exacerbates Acute Renal Ischemic Damage in Anesthetized Dogs. Archives of Surgery, 122, 790-794. http://dx.doi.org/10.1001/archsurg.1987.01400190056011

[50] Ferreira, L., Teixeira-De-Lemos, E., Pinto, F., Parada, B., Mega, C., Vala, H., et al. (2010) Effects of Sitagliptin Treat- 
ment on Dysmetabolism, Inflammation, and Oxidative Stress in an Animal Model of Type 2 Diabetes (ZDF Rat). Mediators of Inflammation, 2010, Article ID: 592760. http://dx.doi.org/10.1155/2010/592760

[51] Matsui, T., Nishino, Y., Takeuchi, M. and Yamagishi, S.I. (2011) Vildagliptin Blocks Vascular Injury in Thoracic Aorta of Diabetic Rats by Suppressing Advanced Glycation End Product-Receptor Axis. Pharmacological Research, 63, 383-388. http://dx.doi.org/10.1016/j.phrs.2011.02.003

[52] Li, L., El-Kholy, W., Rhodes, C.J. and Brubaker, P.L. (2005) Glucagon-Like Peptide-1 Protects Beta Cells from Cytokine-Induced Apoptosis and Necrosis: Role of Protein Kinase B. Diabetologia, 489, 1339-1349. http://dx.doi.org/10.1007/s00125-005-1787-2

[53] Zhang, X., Wang, Z., Huang, Y. and Wang, J. (2011) Effects of Chronic Administration of Alogliptin on the Development of Diabetes and $\beta$-Cell Function in High Fat Diet/Streptozotocin Diabetic Mice. Diabetes, Obesity and Metabolism, 13, 337-347. http://dx.doi.org/10.1111/j.1463-1326.2010.01354.x

\section{Abbreviations \\ DM: Diabetes mellitus \\ ESRD: End stage renal disease \\ I/R: Renal ischemia/reperfusion injury \\ TNF- $\alpha$ : Tumor necrosis factor alpha}


Scientific Research Publishing (SCIRP) is one of the largest Open Access journal publishers. It is currently publishing more than 200 open access, online, peer-reviewed journals covering a wide range of academic disciplines. SCIRP serves the worldwide academic communities and contributes to the progress and application of science with its publication.

Other selected journals from SCIRP are listed as below. Submit your manuscript to us via either submit@scirp.org or Online Submission Portal.
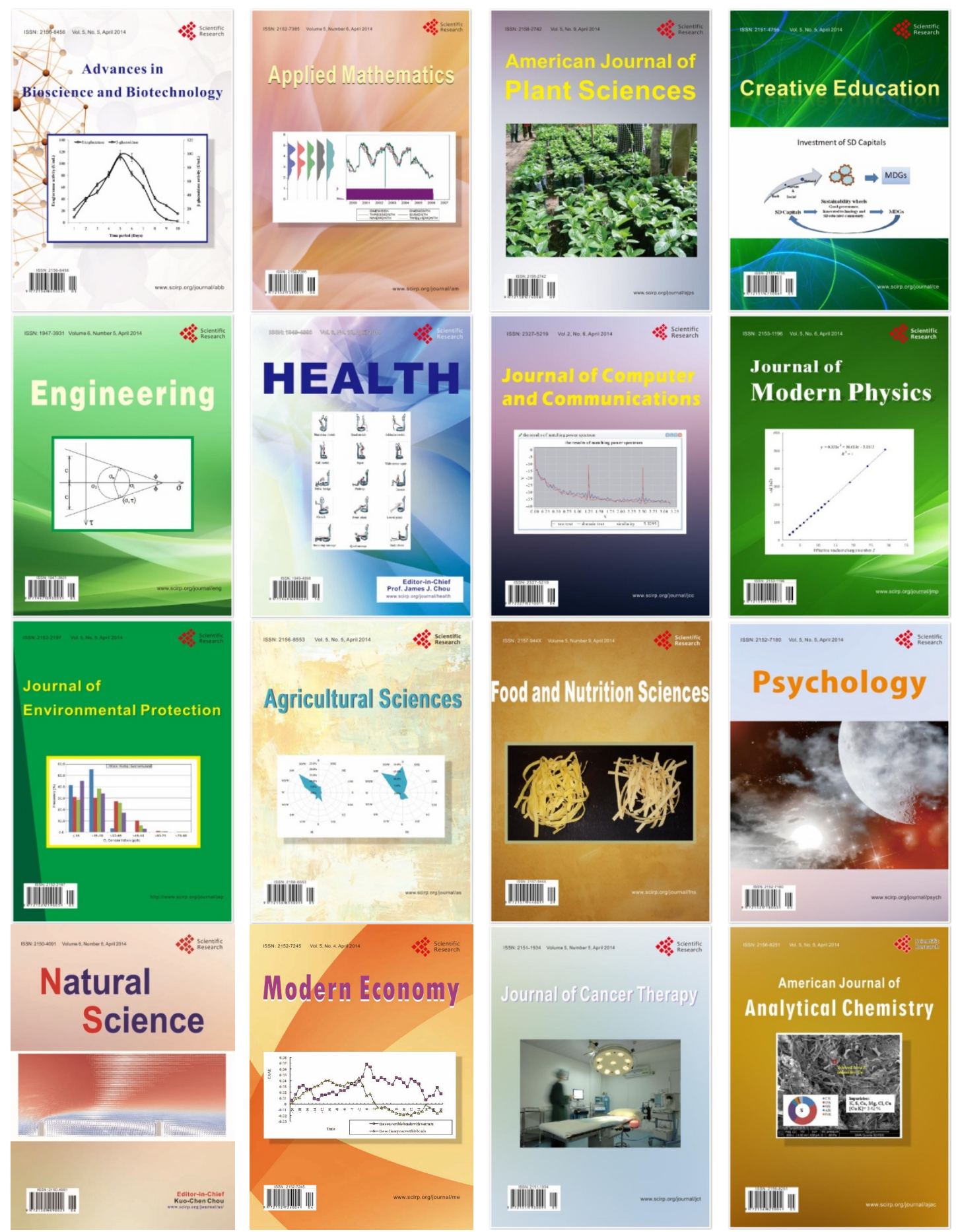